\title{
A COMPARISON OF BONE PRETREATMENT METHODS FOR AMS DATING OF SAMPLES $>30,000$ BP
}

\author{
Sahra Talamo \\ Department of Human Evolution, Max Planck Institute for Evolutionary Anthropology, Deutscher Platz 6, D-04103 Leipzig, \\ Germany. Corresponding author. Email: sahra_talamo@eva.mpg.de. \\ Mike Richards \\ Department of Human Evolution, Max Planck Institute for Evolutionary Anthropology, Deutscher Platz 6, D-04103 Leipzig, \\ Germany. Also: Department of Anthropology, University of British Columbia, 6303 NW Marine Drive, Vancouver, BC, V6T \\ 1Z1, Canada.
}

ABSTRACT. Bone is a commonly used material for radiocarbon dating, yet at ages close to the limit of the method $(>30,000$ $\mathrm{BP}$ ), it is a substantial challenge to remove contamination and produce accurate ages. We report here on the preliminary results of a dating study of 2 bones older than $30,000 \mathrm{yr}$, which were each treated with a suite of pretreatment procedures, including ultrafiltration (Brown et al. 1988). Substantial differences in the ${ }^{14} \mathrm{C}$ ages were observed, which is most likely linked to crucial steps in the removal of contamination both in the bone and in the laboratory. Using a comprehensive sequence of pretreatment procedures, including ultrafiltration, we obtain generally older ages.

\section{INTRODUCTION}

Bone is one of the most important archaeological materials used for radiocarbon dating, but at the same time it is also one of the most difficult materials to date as bone can be susceptible to contamination and is also often degraded. Prior to 1970, whole bone was generally used for dating, and often included bone carbonate, which itself could be postdepositionally contaminated. Longin (1971) proposed a method to isolate bone collagen, which was seen to be a much more stable material and less susceptible to contamination than bone mineral. The main challenge in chemically pretreating bones for ${ }^{14} \mathrm{C}$ dating is therefore to extract collagen and then confirm that the extracted collagen is indeed largely intact and free from contamination, usually through the measurement of a suite of indicators, including C:N ratio, collagen yield, and $\% \mathrm{C}$ and $\% \mathrm{~N}$ in the collagen extract.

Most laboratories use some variation of the Longin (1971) method, but other laboratories have specialized in bone dating and have dramatically improved collagen extraction and purification techniques. For instance, in 1992 the Oxford Radiocarbon Accelerator Unit (ORAU) published the HPLC technique, which is one of the most sophisticated methods to carefully extract and purify amino acids from bone collagen (Van Klinken et al. 1994). Another way to purify the bone samples was proposed earlier by a Canadian research team (Brown et al. 1988), to separate the high-molecular weight $(>30 \mathrm{kD})$ from the low-molecular weight fraction using ultrafiltration, and then produce dates using only the $>30-\mathrm{kD}$ fraction. In 2000, the ORAU adopted this ultrafiltration method (Bronk Ramsey et al. 2000, 2004) for their extracted gelatin, and also included a primary filtration step using an Ezee-Filter ${ }^{\mathrm{TM}}$ (Elkay Laboratory Products Ltd., UK). After various tests of potential contamination from both the ultrafilters and the Ezee-Filters, the ORAU lab found that both of the filters require careful cleaning in an ultrasonic bath (Brock et al. 2007). The ultrafilter has a humectant coating (glycerol) added to maintain the flexibility of the filter. As glycerol can be manufactured from either plant or animal extracts, or alternatively from petroleum processing byproducts, this glycerol needs to be removed as it could add young or old carbon to the sample. Bronk Ramsey et al. (2004) suggested that the best way to eliminate this glycerol without damaging the filter is repeated washes and sonification, and after 3 washes showed that the humectant was effectively removed as shown by no measurable carbon in the eluent. Despite the apparent beneficial role in removing the low-molecular weight fraction of the collagen (Higham et al. 2006), there is an ongoing discussion in the ${ }^{14} \mathrm{C}$ community about the utility and accuracy of ultrafiltration. Hüls et al. 
(2007) tested 2 different ultrafilters, a Vivaspin ${ }^{\mathrm{TM}} 15 \mathrm{R}$ and a Vivaspin 20, using bones of various ages. They showed that in spite of careful cleaning of the ultrafilter, small amounts of contaminant young carbon remained, which probably came from glycerin; hence, they recommended caution in the use of the ultrafilter. In at least one example, dates of mammoth bone samples have been obtained without ultrafiltration, where the ages compare well with contemporary peat and wood (Hajdas et al. 2007).

The ${ }^{14} \mathrm{C}$ activity of the humectant has been shown to be bimodal, i.e. essentially modern or of fossil origin (Brock et al. 2007). For bones older than 30,000 BP, contamination by modern carbon will alter the true age much more dramatically than the addition of ${ }^{14} \mathrm{C}$-dead carbon of a similar size.

At our institution (MPI, EVA Leipzig, Germany), we developed techniques to extract collagen from Pleistocene-age bone for stable isotope analysis and the resultant collagen was often sent to accelerator mass spectrometry (AMS) facilities for ${ }^{14} \mathrm{C}$ dating. In 2005, well-preserved bison and mammoth bones from the North Sea of unknown age were adopted as the long-term quality control material, especially to test for background contamination in the sample preparation, with the assumption that these 2 bones were at least Pleistocene in age, and ideally older than $50,000 \mathrm{BP}$. Initial ${ }^{14} \mathrm{C}$ results from 2 AMS laboratories on collagen prepared at MPI showed the bones to be in the age range of 30,000 to $45,000{ }^{14} \mathrm{C} \mathrm{BP}$, but we observed large discrepancies in the ${ }^{14} \mathrm{C}$ ages between different ${ }^{14} \mathrm{C}$ labs. These inconsistencies could have been caused by deficits in the pretreatment methods that we had established for collagen extraction, by insufficient removal of contamination in the samples, in the AMS measurements themselves, or all three.

We therefore designed a study to investigate the source of these inconsistent dates, and we also compared the results of our pretreatment methods against results from the methods from two of these AMS labs.

\section{METHODS}

We obtained 2 bones, the first a mammoth (S-EVA 2000) and the second a bison (SEVA 2001) from the Pleistocene North Sea plain. Both bones have relatively well-preserved collagen. Bone powder was drilled from the 2 bones and pretreated in 3 different ways (methods A-C) as outlined in Table 1. Method A was the pretreatment method employed when we first ran stable isotope analysis and later on dated the mammoth and bison samples. The bone is decalcified in $\mathrm{HCl}$ over several days while refrigerated $\left(\sim 4{ }^{\circ} \mathrm{C}\right)$ until no effervescence is observed. The gelatinization step is at $\mathrm{pH} 3$ at $70{ }^{\circ} \mathrm{C}$ for $48 \mathrm{hr}$. The ultrafilter (Vivaspin 15, $30 \mathrm{kD}$ ) is rinsed in $\mathrm{NaOH}(1 \times)$ and $\mathrm{H}_{2} \mathrm{O}(4 \times$ ). Method B differs only in the cleaning of the ultrafilter, which was modified by removing the $\mathrm{NaOH}$ cleaning, and adding a 1-hr ultrasonic bath after the third $\mathrm{H}_{2} \mathrm{O}$ rinse. In initial tests, we also used Millipore ultrafilters but in agreement with ORAU (Brock et al. 2007), we found Vivaspin 15 to be better suited for our purposes.

In Method $\mathrm{C}$, the decalcification is at room temperature for $4 \mathrm{hr}$, with an additional $\mathrm{NaOH}$ step to remove humics and followed by an $\mathrm{HCl}$ step to remove potential contamination from modern $\mathrm{CO}_{2}$ taken up by the $\mathrm{NaOH}$. The gelatinization is done at $\mathrm{pH} 3$ but at $75^{\circ} \mathrm{C}$ for $20 \mathrm{hr}$. The ultrafilter is cleaned by centrifuging in $\mathrm{H}_{2} \mathrm{O}(5 \times)$ without the $\mathrm{NaOH}$ rinse, and kept for $1 \mathrm{hr}$ in ultrasonic bath after the third $\mathrm{H}_{2} \mathrm{O}$ rinse. The cleaning is checked by monitoring the carbon level in the eluent.

We also submitted unpretreated samples ( 2 pieces of each bone) directly to the Oxford and Kiel laboratories, which were then pretreated in each laboratory following standard in-house pretreatment methods (Method $\mathbf{D}_{\mathbf{K}}$, Method $\mathbf{D}_{\mathbf{O}}$ ). The specifics of these methods are given below. 
Table 1 Pretreatment steps for all 3 methods.

\begin{tabular}{|c|c|c|c|c|c|c|c|c|}
\hline \multirow[b]{2}{*}{ Method } & \multicolumn{3}{|c|}{ Decalcification } & \multirow[b]{2}{*}{ Gelatinization } & \multicolumn{3}{|c|}{ Cleaning of the ultrafilter } & \multirow[b]{2}{*}{$\begin{array}{l}\mathrm{H}_{2} \mathrm{O} \\
\text { centrifuge }\end{array}$} \\
\hline & $\mathrm{HCl}$ & $\mathrm{NaOH}$ & $\mathrm{HCl}$ & & $\begin{array}{l}\mathrm{NaOH} \\
\text { centrifuge }\end{array}$ & $\begin{array}{l}\mathrm{H}_{2} \mathrm{O} \\
\text { centrifuge }\end{array}$ & $\begin{array}{l}\text { Ultrasonic } \\
\text { bath }\end{array}$ & \\
\hline $\bar{A}$ & $\begin{array}{l}\text { Several days } \\
\text { at } \sim 4^{\circ} \mathrm{C}\end{array}$ & No & No & $\begin{array}{l}\mathrm{pH} 3,70{ }^{\circ} \mathrm{C} \\
\text { for } 48 \mathrm{hr}\end{array}$ & $1 \times$ & $4 \times$ & No & No \\
\hline B & $\begin{array}{l}\text { Several days } \\
\text { at } \sim 4^{\circ} \mathrm{C}\end{array}$ & No & No & $\begin{array}{l}\mathrm{pH} 3,70^{\circ} \mathrm{C} \\
\text { for } 48 \mathrm{hr}\end{array}$ & No & $3 \times$ & $1 \mathrm{hr}$ & $2 \times$ \\
\hline $\mathrm{C}$ & $\begin{array}{l}4 \mathrm{hr} \text { at room } \\
\text { temperature }\end{array}$ & Yes & Yes & $\begin{array}{l}\mathrm{pH} 3,75^{\circ} \mathrm{C} \\
\text { for } 20 \mathrm{hr}\end{array}$ & No & $3 \times$ & $1 \mathrm{hr}$ & $2 \times$ \\
\hline
\end{tabular}

Method $\mathbf{D}_{\mathbf{K}}$, Kiel-Leibniz Laboratory: Demineralization of bone pieces 0.5 to $2 \mathrm{~mm}$ in size with $1 \% \mathrm{HCl}$ at room temperature, keeping $\mathrm{pH}<1$, and then subsequent washes with Milli- $\mathrm{Q}^{\mathrm{TM}}$ water (Millipore Corp.) until $\mathrm{pH}>4$. Then, an extraction was done for $1 \mathrm{hr}$ at room temp with $1 \% \mathrm{NaOH}$, followed by washing with Milli-Q until $\mathrm{pH}<9$, and then again an extraction with $1 \% \mathrm{HCl}$ for $1 \mathrm{hr}$ at room temperature followed by a water rinse. The resulting extract is then hydrolyzed overnight at $\mathrm{pH}=3$ at $85^{\circ} \mathrm{C}$ in a water bath. The gelatin solution is then filtered through a precleaned $0.45-\mu \mathrm{m}$ silver filter. This laboratory normally does not use ultrafiltration because they are still investigating potential contamination by the filters.

Method $\mathbf{D}_{\mathbf{O}}$ : Oxford Laboratory: This method is described fully in Brock et al. (2007).

\section{RESULTS}

The stable isotope data $\left(\mathrm{C}: \mathrm{N}, \delta^{13} \mathrm{C}, \delta^{15} \mathrm{~N}\right.$, and $\% \mathrm{C}$ and $\% \mathrm{~N}$ content) for mammoth and bison collagen is presented in Table 2 for all methods. We do not observe significant differences in these values between the different preparation methods and the parameters indicate well-preserved collagen (DeNiro 1985; Ambrose 1990).

Table 2 Atomic C:N ratio and stable isotope analysis of collagen from the mammoth (S-EVA 2000) and bison (S-EVA 2001) bones. The collagen was prepared according to methods A-C. For $\delta^{13} \mathrm{C}$, the standard is VPDB; for $\delta^{15} \mathrm{~N}$, the standard used is IAEA N1 and N2. Typical analytical precision is $0.1 \%$ for $\delta^{13} \mathrm{C}$ and $0.2 \%$ for $\delta^{15} \mathrm{~N}$.

\begin{tabular}{lllllll}
\hline & Method & $\delta^{13} \mathrm{C}(\%)$ & $\delta^{15} \mathrm{~N}(\%)$ & $\% \mathrm{C}$ & $\% \mathrm{~N}$ & $\mathrm{C}: \mathrm{N}$ \\
\hline Mammoth & & & & & & \\
2000 & $\mathrm{A}$ & -21.1 & 7.0 & 41.9 & 15.4 & 3.2 \\
2000-XXII & $\mathrm{B}$ & -21.2 & 6.8 & 39.4 & 13.9 & 3.3 \\
$2000 \mathrm{D}$ & $\mathrm{C}$ & -21.4 & 6.8 & 44.2 & 16.2 & 3.2 \\
Bison & & & & & & \\
2001 & $\mathrm{~A}$ & -20.8 & 3.1 & 38.8 & 13.9 & 3.3 \\
$2001-$ XII & $\mathrm{B}$ & -20.5 & 2.4 & 40.5 & 14.5 & 3.3 \\
$2001 \mathrm{C}$ & $\mathrm{C}$ & -20.5 & 2.6 & 41.4 & 15.2 & 3.2 \\
\hline
\end{tabular}

Dating results for the mammoth (S-EVA 2000) are given in Table 3a. The collagen prepared at the Max Planck Institute (MPI) by methods A-C was submitted to both Kiel and Oxford for dating. For methods $\mathrm{A}$ and $\mathrm{C}$, separate preparations had to be made to obtain enough material for analysis. For Method B, collagen yields allowed us to split the same collagen sample to be sent to the different labs. The resulting mammoth ages from the different methods and different labs range between 
31,660 and $35,280{ }^{14} \mathrm{C}$ BP with $1 \sigma$ errors between 200 and $510 \mathrm{yr}$. The youngest results are associated with Method A, while methods B and C tend to give older ages (Figure 1). Within each method, the results of methods A, B, and C agree within $1 \sigma$ between the AMS labs of Kiel and Oxford, but for Method $\mathrm{D}$ the results are statistically different. For these samples submitted as bone to the $2{ }^{14} \mathrm{C}$ labs for pretreatment in their laboratories (methods $\mathrm{D}_{\mathrm{K}}$ and $\mathrm{D}_{\mathrm{O}}$ ), the difference between the dates is $2620 \mathrm{yr}$ and the results in the labs do not agree statistically with their respective results of Method C (Figure 1).

Table $3 \mathrm{a}{ }^{14} \mathrm{C}$ results of mammoth samples prepared using methods A to $\mathrm{D}$. Missing values were not reported. The $\delta^{13} \mathrm{C}$ reported is derived from the AMS sample combustion procedure. OxA-V indicates that the material was combusted and graphitized/dated in Oxford, but the chemical pretreatment of the bone was done at MPI.

\begin{tabular}{|c|c|c|c|c|c|c|c|c|}
\hline $\begin{array}{l}\text { S-EVA } \\
\text { mammoth }\end{array}$ & Method & Lab code & $\begin{array}{l}\% \text { yield o } \\
\text { collagen }\end{array}$ & $\begin{array}{l}\text { C content } \\
(\%)\end{array}$ & $\mathrm{pMC}$ & ${ }^{14} \mathrm{C}$ age & $\begin{array}{l}\text { Error } \\
\pm 1 \sigma\end{array}$ & $\begin{array}{l}\delta^{13} \mathrm{C} \\
(\%))\end{array}$ \\
\hline 2000 & $\bar{A}$ & KIA-28337 & & 46 & $1.94 \pm 0.06$ & 31,660 & 240 & -21.2 \\
\hline 2000 & A & KIA-29434 & & 45.5 & $1.90 \pm 0.12$ & 31,820 & 510 & -22 \\
\hline 2000 & A & OxA-V-2166-47 & & & & 31,910 & 200 & -19.7 \\
\hline 2000-XXII & B & KIA-35978 & 3.3 & 48.8 & $1.59 \pm 0.06$ & 33,280 & 320 & -19.1 \\
\hline 2000-XXIIa ${ }^{\mathrm{a}}$ & B & OxA-V-2281-52 & 3.3 & 45.3 & $1.51 \pm 0.05$ & 33,670 & 200 & -21.2 \\
\hline 2000 XXIII & $\mathrm{C}$ & KIA-44753 & 4.2 & & $1.53 \pm 0.06$ & 33,560 & 320 & -23.7 \\
\hline $2000 \mathrm{D}^{\mathrm{a}}$ & $\mathrm{C}$ & OxA-UnK;54 & 9.4 & & $1.50 \pm 0.05$ & 33,733 & 257 & -19.2 \\
\hline $2000 D_{-}^{a}$ & $\mathrm{C}$ & MAMS-10399 & 9.4 & & $1.27 \pm 0.04$ & 35,075 & 260 & $-23.3^{b}$ \\
\hline 2000 & $\mathrm{D}_{\mathrm{K}}^{\mathrm{c}}$ & KIA 29435 & & 38.6 & $1.71 \pm 0.07$ & 32,660 & 350 & -20.6 \\
\hline 2000 & $D_{0}$ & OxA-15908 & & & $1.24 \pm 0.05$ & 35,280 & 340 & -20.5 \\
\hline
\end{tabular}

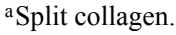

${ }^{\mathrm{b}} \delta^{13} \mathrm{C}$ AMS.

${ }^{\mathrm{c}}$ No ultrafiltration step.

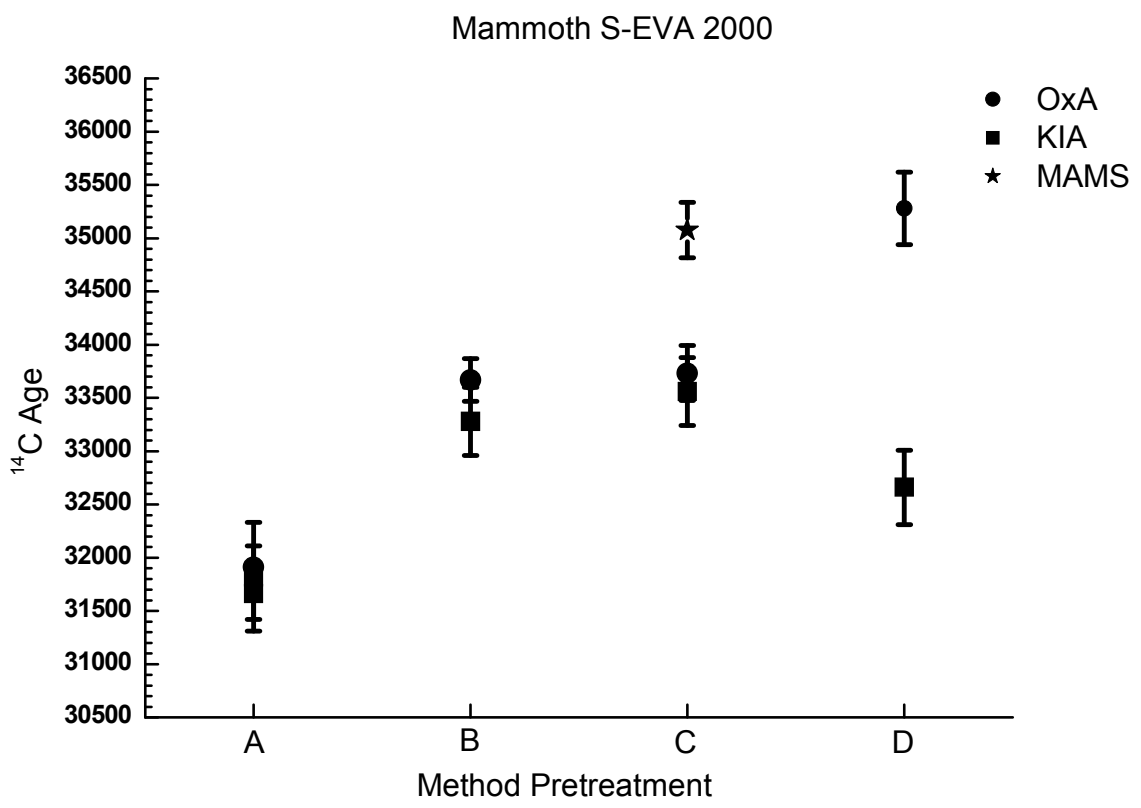

Figure $1{ }^{14} \mathrm{C}$ ages of mammoth bone obtained from methods A to D 
The bison bone (S-EVA 2001) ${ }^{14} \mathrm{C}$ ages range between 37,090 and $>44,800{ }^{14} \mathrm{C}$ BP with errors from 360 to $1630 \mathrm{yr}$ (Table 3b). The results of Method B agree between the 2 AMS labs involved, but they are more than $2000 \mathrm{yr}$ younger than the results of the other methods (except for Method $\mathrm{D}_{\mathrm{K}}$, which is the youngest of the results). The results of methods A and C agree statistically at the $2 \sigma$ level (Figure 2).

Table $3 \mathrm{~b}{ }^{14} \mathrm{C}$ results of bison samples prepared using methods A to D. Missing values were not reported. The $\delta^{13} \mathrm{C}$ reported is derived from the AMS sample combustion procedure. OxA-V indicates that the material was combusted and graphitized/dated in Oxford but the chemical pretreatment of the bone was done at MPI.

\begin{tabular}{|c|c|c|c|c|c|c|c|c|}
\hline $\begin{array}{l}\text { S-EVA } \\
\text { bison }\end{array}$ & Method & Lab code & $\begin{array}{l}\% \text { yield of } \\
\text { collagen }\end{array}$ & $\begin{array}{l}\text { C content } \\
(\%)\end{array}$ & $\mathrm{pMC}$ & ${ }^{14} \mathrm{C}$ age & $\begin{array}{l}\text { Error } \\
\pm 1 \sigma\end{array}$ & $\begin{array}{l}\delta^{13} \mathrm{C} \\
(\% 0)\end{array}$ \\
\hline 2001 & A & KIA 28338 & & 45.5 & $0.49 \pm 0.05$ & 42,660 & 790 & -21.7 \\
\hline 2001 & A & KIA 29436 & & 45.3 & $0.39 \pm 0.09$ & 44,480 & 1630 & -20.4 \\
\hline 2001 & A & OxA-V-2166-48 & & & $0.28 \pm 0.03$ & 47,300 & 900 & -19.3 \\
\hline 2001-XII ${ }^{\mathrm{a}}$ & B & KIA 35982 & 2.5 & 49.6 & $0.69 \pm 0.05$ & 40,200 & 640 & -22.1 \\
\hline 2001-XIIa ${ }^{\mathrm{a}}$ & B & OxA-V-2281-53 & 2.5 & 44.5 & $0.64 \pm 0.03$ & 40,630 & 360 & -20.8 \\
\hline 2001 XIII & $\mathrm{C}$ & KIA-44754 & 7.1 & & $0.34 \pm 0.05$ & 45,740 & 1420 & -21.3 \\
\hline $2001 \mathrm{C}^{\mathrm{a}}$ & $\mathrm{C}$ & OxA-UnK;53 & 3.7 & & $0.43 \pm 0.03$ & 43,674 & 450 & -18 \\
\hline $2001 \mathrm{C}_{-}^{\mathrm{a}}$ & $\mathrm{C}$ & MAMS-10398 & 3.7 & & $0.29 \pm 0.04$ & 47,000 & 1250 & $-21.6^{\mathrm{b}}$ \\
\hline 2001 & $D_{K}{ }^{c}$ & KIA 29437 & & 39.5 & $0.99 \pm 0.07$ & 37,090 & 570 & -19.3 \\
\hline 2001 & $\mathrm{D}_{\mathrm{O}}$ & OxA-15909 & & & & $>44,800$ & - & -20.1 \\
\hline
\end{tabular}

${ }^{a}$ Split collagen.

${ }^{\mathrm{b}} \delta^{13} \mathrm{C}$ AMS.

${ }^{\mathrm{c} N o}$ ultrafiltration step.

Bison S-EVA 2001

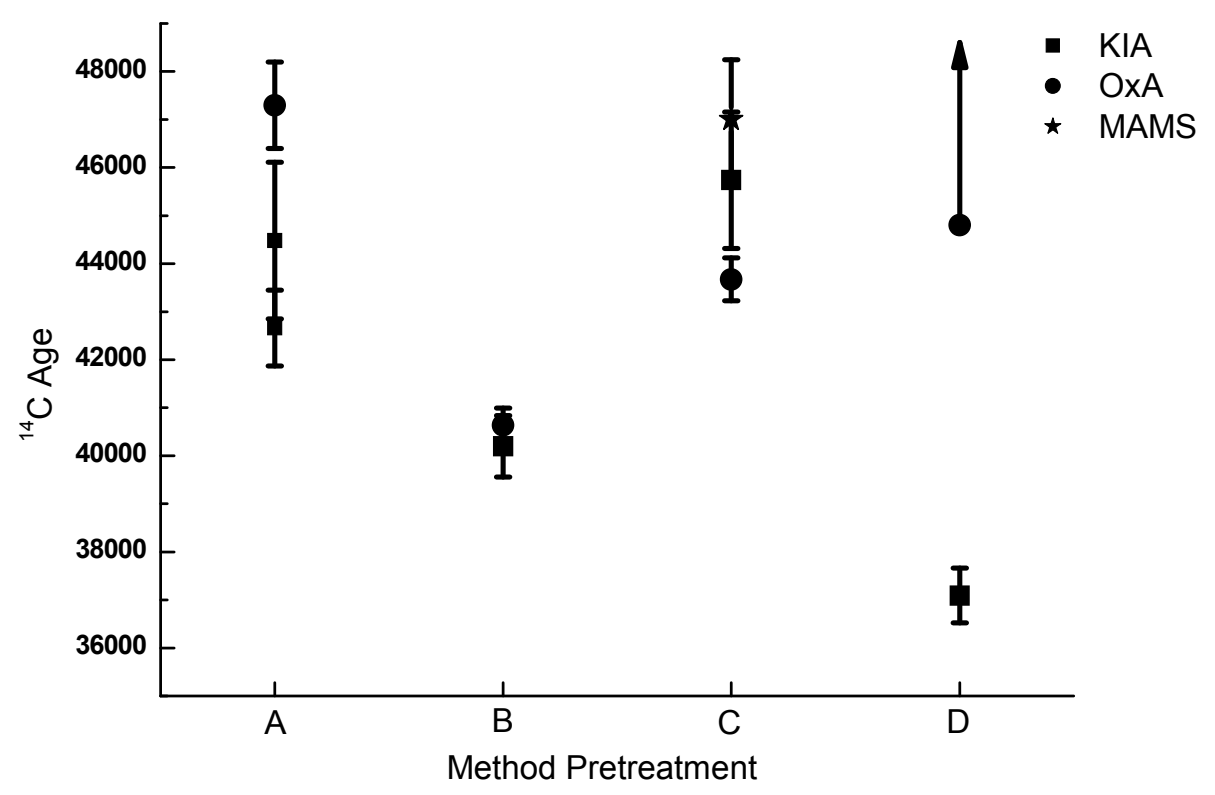

Figure $2{ }^{14} \mathrm{C}$ ages of bison bone obtained from methods $\mathrm{A}$ to $\mathrm{D}$ 
As an additional test of possible contamination in the graphitization stage, we also sent the collagen prepared using what we believe is the most stringent preparation method, Method C, to a third AMS lab, Mannheim (lab code MAMS), to compare the results between the 3 labs. Surprisingly, the Mannheim lab for both the mammoth and bison samples had older ages than both Kiel and Oxford, for the same collagen extract. The combination of Method C preparation in our lab and then subsequent graphite production and AMS measurement in the Mannheim lab resulted in the same, or very similar, older ages as the bone samples prepared and measured entirely in the Oxford lab (Table 3a,b, Figures 1 and 2).

\section{DISCUSSION AND CONCLUSION}

To obtain reliable bone dates, good quality collagen is required, which can be confirmed through the measurement of the $\mathrm{C}: \mathrm{N}$ ratio, yield, $\% \mathrm{C}$, and $\% \mathrm{~N}$. As shown in Table 2, collagen from both of our samples is well preserved for all of the pretreatment methods. There was very little difference in the collagen isotope values and preservation criteria indicators between the 3 methods.

With the pretreatment methods we used, almost all of these criteria remained the same, with the exception of collagen yield. We observed a significant increase in yield when the decalcification in $\mathrm{HCl}$ was performed relatively quickly at room temperature (Method C) compared to Method A that required decalcification for several days at a constant temperature $\left(5^{\circ} \mathrm{C}\right)$. For example, we obtained $50 \%$ more for the bison and up to 3 times more collagen for the mammoth.

The true ages of the 2 bone samples is unknown, but the influence of contamination at ages older than $30,000 \mathrm{yr}$ BP is very asymmetric, with young contamination dominant relative to the original ${ }^{14} \mathrm{C}$ content of an old sample, even at low percent levels of exogenous carbon, contrary to relatively small effect that the addition of ${ }^{14} \mathrm{C}$-free (dead) carbon has (Mook and Streurman 1981). We know that in the recent shipments of the filters the humectant is modern (Brock et al. 2007), so there is good reason to consider the oldest ages the real ones, and younger ages resulting from modern contamination. In a case when modern contamination is substantial in the collagen to be dated, one might even obtain the paradoxical result that the measured ages appear more homogeneous compared to the case when samples of very low ${ }^{14} \mathrm{C}$ activity, without added contamination, are analyzed.

The age results indicate that the 2 bone samples need to be discussed separately. For the mammoth bone (Table 3a, Figure 1), the picture would be consistent if only the results of methods A to C for Oxford and Kiel are considered. They indicate incomplete removal of modern contamination in the collagen of Method A, and the lack of any measurable effect of the $\mathrm{NaOH}$ step, which is the main difference between methods B and C. But the results for Method D, where each of the labs are in full control of all procedures, are clearly incompatible, both among the 2 labs but also compared to the results of these labs with collagen of methods $\mathrm{C}$ and $\mathrm{B}$. This was one of the reasons we then sent an aliquot of the collagen prepared in our lab using Method C to a third AMS lab (Mannheim), which resulted in an age identical to the older ages of Oxford with Method D.

We must conclude that either the ages of Oxford $\left(D_{0}\right)$ and Mannheim $(C)$ are true or the 4 results younger by about $1500 \mathrm{yr}$ are the correct ones. As explained above, a shift to older ages compared to the true age is much less probable than the opposite effect of modern contamination. We therefore conclude that the true age of the mammoth is most likely around $35,000{ }^{14} \mathrm{C} \mathrm{BP}$, and the younger ages as being caused by modern contamination in the AMS labs, e.g. during graphitization.

The bison sample is older than the mammoth; therefore, we expect the effects of contamination to be more severe for this bone (Table 3b, Figure 2). Again, methods $\mathrm{C}$ and $\mathrm{D}_{\mathrm{O}}$ show the oldest ages, 
but Method A has 2 similarly old results as well. An explanation could be that the filters may contain a variable amount of humectant, which might have been removed by the basic cleaning used in Method A. If this is the case, then this means that regular checks on the cleaning efficiency of the ultrafilters are necessary and this is part of methods $\mathrm{C}$ and $\mathrm{B}$. The latter method does not include the $\mathrm{NaOH}$ step to remove humics; therefore, for bones of this antiquity, contamination by humics could alter the ${ }^{14} \mathrm{C}$ age, and thus, the $\mathrm{NaOH}$ step becomes important.

When samples are close to the lower age limit of ${ }^{14} \mathrm{C}$ dating, the low ${ }^{14} \mathrm{C}$ activity level and difficulty of obtaining sufficient and well-preserved collagen means that bone is an especially problematic material to accurately date. In this study, as in earlier exercises (Higham et al. 2006; Hajdas et al. 2007; Hüls et al. 2007), we observed that by using elaborate pretreatment procedures that eliminate both modern laboratory contamination and contamination from degenerated proteins and humic acids we were able to obtain older ages. We still observe discrepancies between the results of different AMS labs, highlighting the many challenges of ${ }^{14} \mathrm{C}$ dating at very low ${ }^{14} \mathrm{C}$ activity.

\section{ACKNOWLEDGMENTS}

We would like to thank Piet Grootes, Thomas Higham, Matthias Hüls, Bernd Kromer, Marie-Josée Nadeau, and Lukas Wacker for providing the AMS dates as well as their advice and expertise. We are especially grateful to Nancy Beavan and an anonymous reviewer for their careful reviews, which improved the manuscript considerably.

\section{REFERENCES}

Ambrose SH. 1990. Preparation and characterization of bone and tooth collagen for isotopic analysis. Journal of Archaeological Science 17(4):431-51.

Brock F, Bronk Ramsey C, Higham T. 2007. Quality assurance of ultrafiltered bone dating. Radiocarbon 49(2):187-92.

Bronk Ramsey C, Pettitt PB, Hedges REM, Hodgins GWL, Owen DC. 2000. Radiocarbon dates from the Oxford AMS system: Archaeometry datelist 30. Archaeometry 42(2):459-79.

Bronk Ramsey C, Higham T, Bowles A, Hedges R. 2004. Improvements to the pretreatment of bone at Oxford. Radiocarbon 46(1):155-63.

Brown TA, Nelson DE, Vogel JS, Southon JR. 1988. Improved collagen extraction by modified Longin method. Radiocarbon 30(2):171-7.

DeNiro MJ. 1985. Postmortem preservation and alteration of in vivo bone collagen isotope ratios in relation to palaeodietary reconstruction. Nature 317(6040): 806-9.

Hajdas I, Bonani G, Furrer H, Mäder A, Schoch W. 2007.
Radiocarbon chronology of the mammoth site at Niederweningen, Switzerland: results from dating bones, teeth, wood, and peat. Quaternary International 164-165:98-105.

Higham TFG, Jacobi RM, Bronk Ramsey C. 2006. AMS radiocarbon dating of ancient bone using ultrafiltration. Radiocarbon 48(2):179-95.

Hüls MC, Grootes PM, Nadeau M-J. 2007. How clean is ultrafiltration cleaning of bone collagen? Radiocarbon 49(2):193-200.

Longin R. 1971. New method of collagen extraction for radiocarbon dating. Nature 230(5291):241-2.

Mook WG, Streurman HJ. 1981. Physical and chemical aspects of radiocarbon dating. In: Mook WG, Streurman HJ, editors. Proceedings of the First International Symposium "14 C and Archaeology." PACT 8:31-55.

Van Klinken GJ, Bowles AD, Hedges REM. 1994. Radiocarbon dating of peptides isolated from contaminated fossil bone collagen by collagenase digestion and reversed-phase chromatography. Geochimica et Cosmochimica Acta 58(11):2543-51. 